\title{
Poemas viajeros. Aportaciones sobre la presencia de la Revolución Griega en la prensa de Argentina y Perú (1822)
}

\author{
Eva Latorre Broto ${ }^{1}$
}

Resumen. En este trabajo se ofrecen nuevos datos sobre algunos poemas dedicados a la exaltación de la Revolución Griega que se publicaron en la prensa argentina y peruana de 1822 tomados de la prensa británica, con el fin de enriquecer el corpus de poesía filohelénica recopilado hasta el momento, y avalar al mismo tiempo la aportación ideológica del filohelenismo a los discursos de construcción nacional e identitaria de las nuevas repúblicas americanas.

Palabras clave: Revolución Griega 1821; filohelenismo en Hispanoamérica; poesía filohelénica británica; poesía filohelénica en español; prensa hispanoamericana del s. XIX; procesos de independencia hispanoamericanos.

[en] Travelling poems. Contributions on the presence of the Greek Revolution in the press of Argentina and Peru (1822)

\begin{abstract}
This paper offers new information about a number of poems praising the Greek Revolution that appeared in the Argentinian and Peruvian press in 1822 from British newspapers. These poems enrich the corpus of Philhellenic poetry compiled so far, and they highlight at the same time the ideological contribution of Philhellenism to the Spanish American discourses of nation and identity building.

Keywords: Greek Revolution 1821; philhellenism in Latin America; British philhellenic poetry; philhellenic Spanish poetry; press in 19th-century Latin America; independence processes in Latin America.

Sumario: 1. Reflexiones iniciales; 2. Poesía fundacional en Argentina y Perú; 3. Clasicismo, republicanismo e indianismo en la construcción de la americanidad; 4. Poesía filohelénica en El Argos: de París a Lima; 5. Poesía filohelénica en La Abeja Argentina: de Jonia a Buenos Aires; 6. Epílogo. 7. Anexo documental.
\end{abstract}

Cómo citar: Latorre Broto, E. (2020) Poemas viajeros. Aportaciones sobre la presencia de la Revolución Griega en la prensa de Argentina y Perú (1822), en Anales de Literatua Hispanoamericana 49, 335-351.

\section{Reflexiones iniciales}

En el campo de los estudios históricos, la aplicación de metodologías de amplio espectro, como la Historia Transnacional, la Historia Global o la Histoire Croisée, ha favorecido relecturas y contextualizaciones de algunos elementos que tradicionalmente se habían venido estudiando desde perspectivas un tanto aisladas o monofocales. Una época muy celebrada por estas metodologías, por no decir que su principal inspiradora, ha sido la Era de las Revoluciones, inicio de la Edad Contemporánea. A lo largo de los ciclos revolucionarios que se sucedieron desde mitad del siglo XVIII hasta mitad del siglo XIX, Europa fue experimentando el desmoronamiento de sus anquilosadas estructuras de poder ante la irrupción de unos discursos ideológicos renovadores que acabarían por permear todo el andamiaje interno de lo que luego se denominó Antiguo Régimen. Si el fenómeno de la Ilustración actuó como desencadenante principal de esa Era de las Revoluciones, la entronización de la Antigüedad Clásica como paradigma de prestigio se erigió en uno de los pilares básicos de la identidad de esa nueva Europa que bajo el signo de las Luces comenzaba a tomar conciencia de sí misma. 
Roma siempre había gozado de presencia en el imaginario del Viejo Continente, por lo que la gran novedad de ese retorno a los clásicos fue el descubrimiento de Grecia, en el que tuvieron mucho que ver, en primer lugar, la institucionalización del estudio del griego en las grandes universidades europeas a partir del Renacimiento - recordemos la máxima Graecum est, non legitur, que menudea en los márgenes de los manuscritos medievales - y, en segundo, los relatos de los viajeros que se adentraron por Oriente para contemplar los venerables vestigios sobre los que se cimentó el postulado de que la Antigua Grecia había sido la única civilización capaz de concebir y materializar la Belleza y la Perfección. A partir de ese momento, lo Griego se convertirá en referente de toda creación humana que pretenda considerarse digna, pues todas las creaciones humanas serán bellas y perfectas en tanto y cuanto imiten a las creaciones griegas.

El Helenismo, la devoción por lo Griego, trascendió la esfera de la filosofía estética hasta acabar impregnando todos los ámbitos de la cultura. El descubrimiento e idealización de la Grecia antigua avanzó mano a mano con la creación de la identidad europea, razón por la que Grecia se asumió como la cuna intelectual de Occidente. Esta concepción perdura a día de hoy, cuando aún se cita con entusiasmo en solidaridad con la difícil situación que atraviesa la Grecia moderna lo que Percy B. Shelley escribió en 1821: "We are all Greeks. Our laws, our literature, our religion, our arts have their root in Greece". La conciencia de esta presunta deuda de Europa con Grecia subyace en la mutación del Helenismo en Filohelenismo, o el convencimiento de que Europa, en agradecimiento por su legado, debía ayudar a Grecia a salir de la postración en la que se encontraba bajo el dominio del Imperio Otomano. Así, un concepto en principio estético acabó incorporando connotaciones políticas claras: el renacimiento de Grecia implicaba nada menos que la modificación de la faz de Europa y un desafío directo al statu quo del poder establecido, siempre legítimo por decisión divina, aunque fuera el del Sultán ${ }^{2}$.

Cuando en la primera oleada de la Era de las Revoluciones se iniciaron los procesos de descolonización americanos con la declaración de independencia de los Estados Unidos en 1776, el clasicismo ya se había transferido al Nuevo Mundo y arraigado con fuerza entre las culturas criollas con el mismo prestigio de que gozaba en sus metrópolis europeas. Los estudios sobre la presencia de la Tradición Clásica en el ámbito americano conforman una bibliografia inabarcable cuyo objetivo, por decirlo de forma muy resumida, es demostrar que la sociedad criolla había alcanzado un grado de desarrollo tan elevado que igualaba a la metrópoli en erudición y era ya capaz de crear su propia epopeya fundacional, conclusión que contribuye a reforzar el argumentario insurreccional para legitimar su decisión de emprender la senda de la independencia ya como sociedades maduras capaces de autogestionarse.

Sin embargo, no ha ocurrido lo mismo con el Filohelenismo. A partir del estallido de la Revolución Griega en marzo de 1821, en su condición de corriente ideológica y política que defendía el derecho de Grecia a su existencia como nación independiente, el filohelenismo es uno de esos elementos que hasta época relativamente reciente se ha estudiado desde perspectivas demasiado acotadas - el filohelenismo francés, inglés, italiano, alemán, ruso...- y demasiado eurocéntricas, con la notable excepción del filohelenismo norteamericano. Este estudio se ha visto muy condicionado además por lo que cada nación aportó en política, en recursos, en voluntarios que acudieran a luchar contra los turcos, y también en textos de la más variada tipología que transmitieran a la opinión pública europea la necesidad de crear esa Grecia libre con el fin de legitimar la intervención aliada de Francia, Gran Bretaña y Rusia en la batalla naval de Navarino en octubre de 1827, cuya victoria decidió la emancipación de Grecia del Imperio Otomano. La aplicación de metodologías de enfoque global ha roto compartimentos estancos y ha demostrado que el filohelenismo constituyó uno de los elementos definitorios de las bases ideológicas del liberalismo trasnacional europeo, pero las aportaciones de las distintas naciones a la libertad griega todavía se siguen sobrevalorando en la prioridad que la crítica otorga al estudio de la expresión del filohelenismo en un espacio concreto.

Las circunstancias impidieron que desde el ámbito hispánico se produjeran aportaciones a la libertad de Grecia. La España del Trienio, aun sintiéndose plenamente identificada con la lucha contra el despotismo que simbolizaba la insurrección griega, se encontraba sumida en sus conflictos internos entre revolución y contrarrevolución y presionada además desde el exterior por las potencias de la Santa Alianza, por lo que no consiguió concretar ninguna medida de ayuda a los griegos, algo imposible ya cuando en octubre de 1823

\footnotetext{
${ }^{2}$ Ésta es una de las ideas básicas del fenómeno del filohelenismo. Remitimos a Zanou (2015, 38-40) por su excelente estructuración teórica del proceso de transformación del Helenismo erudito dieciochesco en el Filohelenismo decimonónico de impacto político. Tolias (2017) elabora el relato del (filo)helenismo desde la Antigüedad hasta finales del s. XIX, ofreciendo un completo repertorio bibliográfico.
} 
Fernando VII recuperó su poder absoluto gracias a la invasión del Duque de Angulema (Latorre 2012). Las nuevas repúblicas americanas, por su parte, se encontraban tan alejadas geográficamente de Grecia como cercanas en ideología, pues ambos procesos de construcción nacional fueron en buena medida coetáneos; de hecho, ya en su momento se equiparó a la Grecia bajo el poder de la Sublime Puerta con la América sometida a la Corona española, y entre los liberales europeos de la década de 1820, asfixiados por la política represiva de la Santa Alianza, América y Grecia eran los únicos espacios en los que aún se podía respirar libertad. Incluso se han analizado en paralelo los procesos de independencia griego y americano en busca de factores comunes y divergencias marcadas por la especificidad de cada región ${ }^{3}$.

Es precisamente esa empatía ideológica entre Grecia y América lo que hace ya necesaria una reflexión de amplias miras sobre la recepción que la Revolución Griega tuvo en esos espacios americanos en pleno proceso de reorganización y, de la misma manera que se ha hecho con la opinión pública europea, analizar el modo en que Grecia, no ya la antigua Grecia, sino la nueva Grecia libre, la alzada en armas, fue presentada ante la opinión pública americana y pasó a formar parte del desarrollo de sus discursos nacionales y de sus construcciones identitarias.

Hasta época reciente las alusiones a la Grecia libre que se iban localizando en el corpus textual hispanoamericano se recogían en dos tipos de trabajos: bien en aquellos que versaban sobre el clasicismo en las culturas criollas, considerándose a un nivel poco menos que anecdótico o pintoresco y quedando diluidas en ese Helenismo que, a su vez, se sumía en el maremágnum de contenidos al que da cabida la Tradición Clásica, o bien en aquellos que estudiaban el romanticismo orientalista en la cultura hispanoamericana ${ }^{4}$. La pionera monografía de Suárez (1984), que estudia las menciones de la Revolución Griega en el Buenos Aires de Bernardino Rivadavia, constituye una loable excepción que ha tardado décadas en ser continuada, y sólo recientemente van saliendo a la luz trabajos sobre la presencia de la Grecia libre en textos de Colombia, Cuba o México5.

Ante tan vasto panorama es necesario comenzar por estudios de caso que permitan ir ampliando perspectiva, pero los primeros estudios globales sobre filohelenismo en la América hispánica elaborados por Latorre (2015 y 2019) han puesto de manifiesto que su presencia no puede disociarse de los discursos nacionales de las nuevas repúblicas, tan imbricados entre sí, y que es posible hablar de un filohelenismo transamericano para cuya descripción todavía quedan muchos datos por aportar. La creación de hemerotecas digitales por parte de bibliotecas nacionales y centros de investigación de todo el mundo está sacando a la luz documentación que antes resultaba inaccesible, de modo que el estudio de este filohelenismo transamericano podrá seguir avanzando en la medida en que avance la digitalización de prensa, archivos y documentos coetáneos.

Así, el objetivo del presente trabajo es aportar algunos datos novedosos sobre la presencia de la Revolución Griega entre los escritos de la élite intelectual de Buenos Aires en 1821 y 1822, analizada ya por

${ }^{3}$ Por señalar una obra de la época de enorme trascendencia a este respecto, podemos citar Vrai Système de l'Europe relativement à l'Amérique et à la Grèce par M. de Pradt, Paris, 1825, traducida en ese mismo año al español para su difusión en América. Por otra parte, hasta donde sabemos, el primer estudio moderno sobre Grecia e Hispanoamérica es Stadtmüller, George. "Paralelos y relaciones entre la revolución emancipadora de Latinoamérica y el filohelenismo", Congreso de Academias de Institutos Históricos sobre el pensamiento constitucional de Latinoamérica (18101830). Sesquicentenario de la Independencia de Venezuela, Caracas 1962, vol. II, pp. 154-155. El autor publicó después "Die lateinamerikanische und die griechische Unabhängigkeitsbewegung. Ein historischer Vergleich”, Saeculum, n 33, 1982, pp. 74-87. Mención aparte merecen los numerosos trabajos en los que el profesor chileno Miguel Castillo Didier ha estudiado en paralelo las figuras de los precursores Rigas de Velestino y Francisco de Miranda, que no recogemos aquí por ser de muy fácil acceso en red. Una visión renovada de este paralelismo, si bien centrada en Colombia, en los estudios de De la Peña Jiménez, Luis Alfredo. "Exporting the Revolution: Social Mobility and Transmission of Ideas during the Independence Wars of Colombia and Greece", Paper presented at the 12th Graduate Conference in European History (GRACEH) April 26th, 2018. https://www.academia.edu/36589918/; "The Independence Processes of Greece and Colombia: Topics and Possibilities of Comparison", Global Histories 5.2 (November 2019), pp. 134-144. https://www.academia.edu/41405383/; "Libertad o Muerte: Las guerras post-napoleónicas en Latinoamérica y los Balcanes. El caso de Colombia y Grecia”, Comunicación en VII Encuentro Internacional de Jóvenes Investigadoras e Investigadores en Historia Contemporánea - Universidad de Granada, 5-7 de septiembre de 2019. https://www.academia.edu/41718226/.

${ }^{4}$ Galí Boadella, Montserrat. "Del orientalismo ilustrado al orientalismo romántico: Oriente en las revistas mexicanas de la primera mitad del s. XIX", en Curiel, Gustavo. Orientes-Occidentes: el arte y la mirada del otro, México: Universidad Nacional Autónoma de México, 2007, pp. 615-640; Taboada, H. G. Hernán. "La sombra del Oriente en la Independencia americana", en Nagy-Zekmy, Sylvia (ed.). Moros en la costa: Orientalismo en Latinoamérica, Madrid-Frankfurt: Iberoamericana, 2008, pp. 25-40.

5 Gutiérrez Ardila, Daniel. "La République de Colombie face à la cause des Grecs", en Hébrard, V.-Verdo, G., Las independencias hispanoamericanas. Un objeto de historia, Madrid: Casa Velázquez, 2013, pp. 305-320. https://www.academia.edu/28970136/; Latorre Broto, Eva. "Contribuciones al estudio del filohelenismo en Hispanoamérica: Cantos a la Grecia libre en la Gran Colombia", Byzantion Nea Hellás, n' 39, 2020, pp. 317-344; de la misma: "Grecia como camino hacia la libertad: el filohelenismo de José María Heredia", Anales de Literatura Hispanoamericana, $\mathrm{n}^{\circ}$ 42, 2013, pp. 279-296. http://dx.doi.org/10.5209/rev_ALHI.2013.v42.43668; Miranda Cancela, Elina. "La lucha por la independencia griega en el imaginario poético cubano del XIX", Rialta Magazine (septiembre 2018), https://rialta.org/la-lucha-por-laindependencia-griega-en-el-imaginario-poetico-cubano-del-xix/ 
Latorre (2019 I, 541-571), y ponerlos en relación directa con la primera manifestación del filohelenismo en el Perú del general José de San Martín, estudiada en (ibidem, 573-598), con el fin de seguir ofreciendo materiales que ayuden a profundizar en el estudio del filohelenismo transamericano.

\section{Las colecciones de poesía patriótica fundacional en Argentina y Perú}

La Ilustración asumió como principio didáctico básico la máxima horaciana delectando pariterque monendo, que parecía acuñada ad hoc para lograr su objetivo de difundir las luces y el conocimiento mientras formaba el buen gusto y, lo que es más importante, el criterio, de una clase lectora que se transformará en opinión pública y cuya maduración política traerá consigo el trascendental cambio de mentalidad de súbdito a ciudadano, el desencadenante del proceso revolucionario. El inductor directo de este cambio será la figura que produce los textos, el literato, quien también se ha hecho consciente de que la pluma otorga a su mano el mismo poder, o mayor aún, del que le otorga la espada si sabe poner a su servicio el hasta entonces inusitado alcance que le facilita la generalización de la prensa, ya sea periódica, folletos u hojas volantes, como único medio de comunicación de masas en los nuevos espacios públicos. En el momento en que el literato adquiere conciencia de que su responsabilidad social es directamente proporcional a su notoriedad pública, el didactismo de la literatura ilustrada comenzará a incorporar nuevos contenidos que lo acabarán transformando en educación cívica y, en última instancia, adoctrinamiento político. La propuesta, también horaciana, de mezclar lo útil y lo agradable —utile dulci - contribuirá al surgimiento de la poesía patriótica como vehículo de expresión de las aspiraciones colectivas y la convertirá en la principal herramienta para forjar un imaginario común que sustente las nuevas identidades en construcción, hasta llegar al punto en que "La poesía fue un arma en el arsenal de los libertadores", como escribió Luis Monguió $(1972,13)$.

La bibliografía crítica sobre la asunción de funciones cívicas y políticas por parte del escritor en el tránsito de la Ilustración al Romanticismo, y más específicamente en el ámbito americano de las luchas por la independencia, resulta tan inabarcable como la bibliografía sobre Tradición Clásica. Esta vinculación entre literatura y poder tiene en Argentina uno de sus más señeros exponentes en la compilación de poesía patriótica La Lira Argentina, editada en Francia en 1824 a pesar de que su pie de imprenta reza Buenos Aires, y muy ilustrativa a este respecto por los poemas que la componen y también por las vicisitudes que llevaron a su creación, relatadas en la Introducción a la obra que hizo Pedro Barcia (La Lira 02, XI-XXIV). Dado que son ampliamente conocidas (vd. v. gr. Chenot 2000, 171-178, De Lorenzo 2004, 131-132), aquí nos limitaremos a subrayar aquellos aspectos que resulten de interés para el tema que nos ocupa.

Con el fin de inmortalizar la exaltación nacional surgida a raíz de la batalla de Chacabuco, que el 12 de febrero de 1817 se saldó con la victoria del Ejército de los Andes del general José de San Martín sobre el Ejército Realista de Chile, el chileno fray Camilo Henríquez planteó la necesidad de reunir en una publicación oficial todos los poemas que habían alimentado el ánimo en las luchas por la libertad a modo de piedra fundacional de la nueva identidad americana, pues "todas las naciones libres poseen colecciones de este género". Sin embargo, el proyecto no se concretó y aquellos cantos siguieron dispersos en sueltos, periódicos, poemarios privados y la memoria del pueblo.

Esta iniciativa se retomará después en Buenos Aires desde las más altas esferas políticas por los mismos intelectuales que crearon esos cantos triunfales durante los años más duros de la guerra. La Generación de Mayo, los Poetas de la Revolución, Vicente López y Planes, Esteban de Luca, Juan Ramón Rojas, fray Cayetano Rodríguez, Juan Crisóstomo Lafinur, Antonio Sáenz y Juan Cruz Varela, entre otros, acabaron asumiendo finalmente la consolidación cultural de la independencia.

Cuando el 19 de julio de 1821 el general Martín Rodríguez, gobernador de la provincia de Buenos Aires, nombró ministro de Gobierno a Bernardino Rivadavia, los Poetas de la Revolución apoyaron su proyecto centralista e ilustrado desde cabeceras como El Argos de Buenos Aires, que ya había comenzado a publicarse el 12 de mayo de 1821 y que está considerado entre los mejores periódicos de la década (Lescano 2015, 137139), y también mediante instituciones que definirían los valores que debían regir la nueva realidad, siendo la más relevante la Sociedad Literaria de Buenos Aires. Fundada en enero de 1822, en abril lanzó la que será la primera revista cultural de la nación, La Abeja Argentina, en cuyo prospecto sus redactores expresan con plena conciencia la trascendencia política de su labor: "Nos proponemos generalizar por medio de este periódico aquellos conocimientos que han acelerado en otros pueblos su organización social" (La Abeja Argentina, $\mathrm{n}^{\mathrm{o}} 1,15 / 04 / 1821,4686-4688$ y 5245$)$.

Entre estos esfuerzos por construir una cultura de Estado, Rivadavia retoma en mayo de 1822 el proyecto inspirado por el espíritu de Chacabuco y encarga a la Sociedad Literaria recopilar todos los "rasgos poéticos" producidos desde 1810, lo que: 
No sólo contribuirá a elevar el espíritu público, sino a hacer constar el grado de buen gusto en literatura a que este país ha llegado en época tan temprana; la armoniosa energía con que ha sentido la dignidad a que subía; y lo que debe esperarse de la disposición de sus habitantes.

El fondo de guerra del Estado garantizaba la edición, señal de su trascendencia política, pero a mediados de 1824 cesa el mandato de Rodríguez y con él el ministerio de Rivadavia y la Sociedad Literaria, que dejó una Colección de poesías patrióticas que no llegó a circular (Barcia 2001, 118-121). Gracias al empuje de Ramón Díaz, La Lira Argentina cubrirá ese vacío de poesía nacional. Una buena prueba de su equivalencia funcional es que ambas obras abren con la Marcha patriótica de López y Planes que en 1813 se decretó como Himno nacional, cuyos ecos resonaban incluso en Lima.

En el caso de Perú, esa labor fundacional de recopilación de poesía patriótica como respaldo de la ideología que desea implantar un nuevo poder triunfó mucho antes que en La Plata. Por los días en que Rivadavia era nombrado ministro en Buenos Aires, el 12 de julio de 1821 el general San Martín hacía su entrada en Lima al mando de la Expedición Libertadora de Perú, organizada en principio por las Provincias Unidas del Río de la Plata y Chile, y el día 15 firmaba el Acta de Independencia, siendo designado Protector del Perú y asumiendo todos los poderes sobre las regiones ya libres del virreinato. Los patriotas limeños estallaron en odas, romances, canciones patrióticas y loas en honor al general argentino en las que denostaban a sus antiguos opresores y expresaban su júbilo ante la libertad, y que quedaron dispersas en sueltos y periódicos de efímera existencia. Gracias también a la iniciativa de otro joven patriota, se cree que el sargento Andrés Negrón, periodista arequipeño, en junio de 1822 vio la luz la Colección de algunas poesías publicadas desde la entrada del Ejército Libertador en la Ciudad de los Libres, que recoge piezas de algunos de los miembros más insignes de la sociedad criolla que firmaron el Acta de Independencia, como José Manuel Valdés, Manuel Bartolomé Ferreyros, Felipe Llanos o Santiago Negrón, y respaldaron a San Martín en la refundación política y cultural del nuevo Perú (Homenaje, 8-11).

\section{Clasicismo, republicanismo e indianismo en la construcción de la americanidad}

La íntima imbricación entre los procesos independentistas americanos tiene su reflejo material en esta poesía guerrera compartida, pues tanto en La Lira se canta a los patriotas de Chile y Perú, como en la Colección se incluyen piezas argentinas de La Lira, como, por ejemplo, la Marcha patriótica de López y Planes que comienza:

Oíd mortales el grito sagrado

Libertad, libertad, libertad;

Oíd el ruido de rotas cadenas;

Ved en trono a la noble igualdad.

Se levanta en la faz de la tierra

Una nueva gloriosa nación,

Coronada su sien de laureles

$\mathrm{Y}$ a sus plantas rendido un león.

A la que se añade la emotiva nota:

Esta divina canción que tantas veces ha llenado de entusiasmo en nuestro teatro a los concurrentes debe ocupar aquí un lugar, aunque nacida en otro suelo (Homenaje, 54).

Resultaría especialmente interesante reconstruir el viaje de estos poemas por los caminos de América durante las guerras de independencia, pero si recorrieron miles de kilómetros y en cada lugar se sintieron como propios fue, precisamente, porque vehicularon las aspiraciones de una "Nación criolla" que no veía fronteras en América porque su conciencia de clase privilegiada transamericana era su única patria y aún compartía un objetivo único, la independencia (Díaz-Caballero 2005, 68-69). En su necesidad de diferenciarse de la casta peninsular, la poesía patriótica fue la herramienta perfecta para inculcar un imaginario con el que se identificara toda la nación americana, pero Barcia señala la gran paradoja que implica celebrar la ruptura política con España por medio de la tradición poética y la lengua recibidas de la herencia colonial. Así, los Poetas de la Revolución construirán la Epopeya americana sobre los mimbres del clasicismo y celebrarán la fundación de un imperio nuevo a través de un lenguaje que reflejará dos mundos 
en conflicto: lo peninsular se opone a lo americano, los realistas se enfrentan a los patriotas, el tirano al pueblo soberano, el invasor a los hijos de la patria, la opresión a la libertad y las cadenas al gorro frigio ( $L a$ Lira 02, LXXVI-LXXX).

Esta imaginería política está importada del discurso revolucionario francés, del que también se toma prestado lo que, dentro del corpus de la Tradición Clásica, debe diferenciarse como Neoclasicismo jacobino, concepto aislado por el crítico argentino Arturo Berenguer (1947, 153-186) y que Latorre (2019 I, 127-133 y 694-695) considera uno de los elementos definitorios de los discursos revolucionarios americanos y europeos. Los ideólogos de la Revolución Francesa centraron su admiración por el mundo antiguo en unos motivos muy concretos, la Roma republicana y las repúblicas griegas, Tebas, Atenas, Esparta, y, sobre todo los momentos estelares de las Guerras Médicas, las batallas de Maratón (490 a.C.), Termópilas y Salamina (480 a.C.), en las que los griegos encararon los infinitos ejércitos de los reyes persas Darío y Jerjes con arrojo y abnegación. Los caudillos griegos —-Leónidas, Temístocles, Milcíades, Arístides...- que lo sacrificaron todo por defender las leyes y la forma de vida de sus polis, en definitiva, su tierra y su agua, encarnaron el paradigma que debe emular todo ciudadano que defienda su libertad frente al tirano que quiere arrebatársela, aunque eso implique entregar la propia vida en el altar del Bien común. Nada mejor que el sacrificio de Leónidas y sus Trescientos en las Termópilas, que salvó a toda Grecia de caer bajo el despotismo persa, para ilustrar el lema Libertad o Muerte que sustenta todo el discurso revolucionario transnacional. En este sentido, la identificación de lo americano con lo griego-espartano y de lo persa con lo íbero-español que se desgrana de forma recurrente en La Lira Argentina no debe ser asumido sólo como una muestra erudita de la cultura clásica de los Poetas de la Revolución, sino como un recurso más al servicio de esa confrontación sobre la que se construyó la conciencia de la identidad americana libre frente al Otro, el español déspota e invasor.

$\mathrm{Y}$ en este punto vuelve a darse una nueva hibridación entre dos conceptos en principio irreconciliables y sólo posible en un mundo en gestación: la asimilación de los símbolos republicanos al indio americano ${ }^{6}$. El incaísmo y el indianismo funcionaron como la ficción orientadora de la nación criolla hacia un pasado americano común que les otorgaría la diferencia radical y definitiva frente a lo español peninsular creando un universo exclusivo de lo americano que trasciende la anécdota localista (De Lorenzo 2004; Díaz-Caballero 2005). La idealización del Imperio Inca como una sociedad inocente, primigenia y feliz, regida por reyes sabios y justos, que vivía en comunión con la Naturaleza y que fue destruida por la avaricia y crueldad de los conquistadores, vertebrará buena parte de toda esa poesía patriótica americana y permitirá ir un paso más allá del lema revolucionario: una vez superada la muerte y conseguida la libertad, el siguiente paso es la venganza. Sólo la venganza será capaz de dar satisfacción a los manes de los ancestros para que el Imperio Inca renazca con todo su antiguo esplendor.

La dicotomía Libertad/Despotismo, la confrontación contra un tirano extranjero y el renacimiento de una nueva Edad de Oro fueron también los elementos clave del discurso sobre el que se articuló la Revolución Griega. Los americanos ya se habían identificado tanto en virtud como en valor con los griegos antiguos, por lo que resulta lógico que se solidarizaran íntimamente con la lucha que emprendían los griegos modernos, legitimada por los mismos argumentos que habían legitimado la suya propia.

\section{Poesía filohelénica en EI Argos: de París a Lima}

La primera noticia que hemos localizado hasta ahora sobre la Revolución Griega se encuentra en El Argos del 17 de julio de 1821:

GRECIA - Morning Chronicle. Abril 6- Tenemos que anunciar un evento muy import[ant]e. Cartas fidedignas de Corfú aseguran que en las islas griegas ha habido una insurrección formidable [...]. (El Argos, $\mathrm{n}^{\mathrm{o}}$ 11, 78).

\footnotetext{
${ }^{6}$ BurUCÚA - JAUREgUi - MALOSETTI - Munilla (1990: 149), describen el mapa alegórico elaborado en plata y oro que las damas altoperuanas de Potosí regalaron al general Belgrano en 1813 con la figura de un indígena blandiendo una pica cubierta por un gorro frigio. Asimismo, el escudo de las Provincias Unidas del Río de la Plata, encargado por Rivadavia durante el Primer Triunvirato y atestiguado por primera vez en 1813, presenta el gorro frigio, la pica y dos manos entrelazadas en señal de fraternidad, todo ello combinado con la imagen de Inti, el dios Sol de los incas, símbolo de regeneración.
} 
El 6 de marzo —el 21 de febrero, según el calendario juliano que regía el mundo ortodoxo- Aléxandros Ipsilandis se alzó contra el Sultán en Valaquia y Moldavia, frontera entre los imperios Ruso y Otomano. Su iniciativa fracasó, pero la insurrección se extendió por el Peloponeso y las islas, de modo que cuando la noticia llega a América del Sur, cinco meses después, la Revolución ya está afianzada. A partir de entonces, El Argos irá seleccionando las noticias más relevantes sobre los sucesos de Oriente. Por citar un ejemplo, en

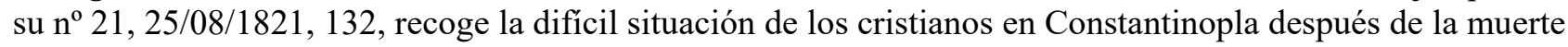
del Patriarca, que el Sultán había ejecutado a modo de castigo ejemplarizante en represalia por la Revolución.

Gracias a que los redactores del Argos suelen citar sus fuentes, sabemos que este artículo apareció en el Times londinense del 29 de mayo. Si tenemos en cuenta que la primera noticia sobre Grecia está tomada del Morning Chronicle, este detalle cobra importancia, pues muestra que la inmensa mayoría de textos sobre la Revolución Griega proceden de la prensa británica progresista. El Morning, en concreto, era editado por el grupo whig más radical del Parlamento inglés que mostró una firme defensa tanto de la independencia de América como de la Revolución Griega, oponiéndose a periódicos conservadores más en línea con la prensa contrarrevolucionaria de la Santa Alianza.

Por otra parte, el Argos suele ofrecer poesía siempre de contenido político, como el Soneto a la muerte de Matías Patrón (Argos, $\mathrm{n}^{\mathrm{o}} 3$, 26/01/1822, 4) o el canto limeño La palomita en honor del general San Martín (Argos, $\mathrm{n}^{\mathrm{o}}$ 19, 23/03/1822, 2), lo que demuestra que, cuando los redactores deciden incluir un poema, su elección nunca es casual y siempre está al servicio del mensaje que quieren transmitir. En este sentido, resulta especialmente relevante que en el $n^{\circ} 7$ del 09/02/1822, más de la mitad de la segunda página esté dedicada a la Revolución Griega a partir de noticias del Morning, del Times, de La Aurora de Filadelfia y de prensa francesa sin especificar, con pasajes como el siguiente, que merece la pena transcribir completo pese a su extensión:

Papeles Franceses. [...] El espectáculo que presenta hoi la Grecia abandonada a sí misma es verdaderamente imponente. Estaba sin armas, sin municiones, sin útiles de guerra, sin navíos; y sus soldados, como los antiguos héroes del país, no tenían sino hondas y palos. Pero así ha vencido ya dos veces sin ayuda de nadie, y destruido e incendiado dos escuadras turcas; por sí sola ha tomado casi todas las fortalezas del Archipiélago, y los Turcos se han rendido con toda humillación, entregando armas y municiones que van a destinarse contra ellos. ¿Qué es lo que han opuesto hasta ahora a estas victorias los descendientes de Saladín, esos fieros sectarios de Mahoma? Nada sino asesinatos odiosos egecutados en mugeres, niños y viejos y la sangre del pueblo quieto y sin defensa que ha perecido en Smyrna y Constantinopla.

El relato está diseñado para conmover al público y despertar tanta admiración por los griegos, que con hondas y palos, "como los antiguos héroes del país", han logrado vencer a ejércitos formidables, como odio por los cobardes turcos, que sólo son capaces de resarcirse de su humillación masacrando al pueblo desvalido. Cierra este apartado con un poema que funciona como la apoteosis final: La Grèce ( $v d$. infra en Anexo, Texto 1 datos sobre origen del poema y su transmisión textual a través de la prensa europea).

El poema se presenta en versión francesa firmado por "Un Liberal" y la referencia "Morning Chronicle, Nov. 2", para, a continuación, ofrecer la traducción en español bajo el título de La Grecia. La voz poética inicia la pieza con un enérgico "Álzate", que parece apelar directamente al lector, para pasar a mostrarle los mares, los campos y las montañas que son los escenarios naturales de las míticas batallas de Salamina, Maratón y las Termópilas, espacios impregnados de inmortalidad que cobran vida por sí mismos y a los que una divinidad les hace gritar: Gloria, Libertad, Venganza. El poema, en efecto, está tomado del Morning Chronicle, $\mathrm{n}^{\circ} 16393,3$, del 2 de noviembre de 1821, y varias son las razones que otorgan a esta pieza una gran importancia no sólo para el filohelenismo americano, sino también para la literatura filohelénica en general.

En primer lugar, la atención que los redactores le han prestado, seleccionándola, traduciéndola y dándole espacio para que aparezca en original y traducción, evidencia un interés especial en que alcance a todo el público posible, y no sólo al que pudiera leer francés, lo que invita a indagar sobre quién pudo ser su traductor y qué mensaje quería transmitir. En 1821, el primer redactor del Argos fue Santiago Wilde, pero en 1822 sus redactores se turnaban entre los miembros de la Sociedad Literaria (Lescano 2015, 140), de modo que resulta difícil inclinarse por un nombre en concreto. En cualquier caso, fue uno de esos Poetas de la Revolución, cualquiera de los autores de la poesía patriótica que se recogió en la Colección y en La Lira y que creó ese imaginario americano común sobre tres líneas maestras: el clasicismo como referente de prestigio, el neoclasicismo jacobino como reivindicación de la ciudadanía libre contra el tirano, y el indianismo / incaísmo como marca definitoria de lo americano frente a lo español / peninsular, lo que nos 
conduce directamente al mensaje. Con su evocación de la Grecia antigua, la mención de sus batallas más célebres y la vivificación de unos espacios mitificados inspirados por un dios iracundo que les hace clamar no sólo gloria, no sólo libertad, sino también venganza, exigencia añadida e irrenunciable del incaísmo, $L a$ Grecia se adapta como un guante a los postulados de la poesía americana de la independencia.

La sed de venganza - ya fuera retórica o real-, dominaba cualquier expresión de ese patriotismo americano desde mucho tiempo atrás. Por otra parte, no se puede olvidar que en 1822 la independencia en La Plata ya era un hecho, mientras que en Perú, aunque Lima ya hubiera sido liberada por San Martín, el frente de guerra seguiría todavía abierto hasta que en diciembre de 1824 se librara la batalla de Ayacucho. En enero de 1822, el coronel Carratalá, jefe del Ejército de Lima, decreta la destrucción del pueblo de Cangallo por ser "asilo de asesinos y guarida de ladrones", y que nada se construirá sobre su solar para que desaparezca por siempre de la memoria de los hombres. La noticia corrió como la pólvora, y El Argos no sólo publicó el decreto en su n ${ }^{\circ} 20,27 / 03 / 1822$, sino que en el siguiente, 30/03/1822, ya insertó un enérgico poema, "Con el objeto de exaltar más y más el patriotismo de los Americanos":

¡Venganza eterna! ¡Sin piedad, venganza!!!

Hijos del Sol, ¿qué hacéis? Ahora, ahora

Renazca el odio y el rencor inmenso

A que provoca la feroz matanza,

La sed de sangre que sin fin devora

A los tigres de la Iberia [...]

Entre ruinas y ceniza

Un pueblo de patriotas agoniza.
[...] El fiero hispano

Estirpe atroz del execrado Atila,

En el Perú desesperado brama,

$\mathrm{Y}$ en su última impotencia deshumano

Con bárbaro furor, quema, aniquila

Y se goza feroz al ver la llama. [...]

Ya vengarte juramos;

Vengarte, sí, y a la venganza vamos.

Tanto el tema del feroz enemigo que, en la humillación de su derrota, se ceba con los inocentes, como la exigencia de justa venganza ante tales atropellos, coincidían de pleno con la imagen que el Argos proyectaba de la Revolución Griega ante la opinión pública americana, vinculando emocionalmente a americanos y griegos. Hablamos de opinión pública americana porque el Argos gozaba de enorme circulación, como lo demuestra el hecho de que este poema, que escribió Juan Cruz Varela aunque apareció sin firma, se incluyera con la misma entradilla con la que se publicó en El Argos en la Colección de algunas Poesías publicadas desde la entrada del Ejército Libertador en la ciudad de los libres que vio la luz en Lima en honor de San Martín ${ }^{7}$.

El 23 de junio de 1822, el Correo Mercantil, Político-Literario de Lima inserta en su $n^{\circ} 33$ el anuncio de esa Colección con el siguiente comentario:

La Colección de Poesías que presentamos al público, si carece de aquellas imágenes y pensamientos sublimes características a esta clase de composiciones, abunda en ideas adecuadas a nuestra situación política, y despierta aquellos sentimientos fuertes que animarán a los pueblos que se encontrasen en iguales circunstancias que nosotros. El odio a los tiranos y a la tiranía es su objeto principal [...].

Este anuncio está precedido de La Grecia, que parece íntimamente unido al poemario patriótico, pues ambos textos forman un solo bloque bien diferenciado de los artículos anterior y posterior por separadores tipográficos, pero la paradoja reside en que ni siquiera está incluido en la Colección. Lo cierto es que la presencia en Lima de este poema resultaba un tanto enigmática. Monguió $(1961,97)$ lo cita a vuelapluma como prueba temprana del romanticismo en Perú, pues lo considera una "traducción bastante parafraseada" de unos versos de The Giaour, de Lord Byron, pero no dice de qué pasaje. Latorre (2019 I, 574-578) analiza las posibles razones que condujeron a la inclusión de La Grecia en el Correo y postula que el original podrían ser los versos 103-127 de The Giaour, a fragment of a Turkish Tale, Londres, 1813, si bien observando que los únicos nexos entre ambos poemas son elementos aislados, como la voz poética que grita a su interlocutor un imperativo “¡Álzate! / Arise!”, y le muestra los espacios de Salamina y las Termópilas, y,

${ }^{7}$ El poema se incluyó en Homenaje, 108-109 bajo el título Venganza, y también en La Lira Argentina, 418-419, sin título ni nombre de autor (La Lira 01, 5118-5119). Por Barcia sabemos que también se recogió en la Colección de Poesías Patrióticas de la Sociedad Literaria que no llegó a circular, donde ya aparecía el nombre de Juan Cruz Varela (La Lira 02, 535-536). 
sobre todo, la vida propia que cobran esos espacios en virtud de su antigua gloria. Tanto la inclusión de Maratón, como la exigencia final de "iVenganza!", serían innovaciones del traductor peruano, por lo que concluye que no debe hablarse de traducción parafraseada, sino de recreación libérrima a partir de unos motivos concretos sobre los que se construye un poema a medida del discurso patriótico imperante.

La constatación de que La Grecia no es una (re)creación original peruana, sino que está tomada del Argos, arroja luz sobre la procedencia del poema, cuestionando el argumento de Monguió sobre el romanticismo en Perú, al menos por influencia directa de Byron. Por otro lado, ahora también sabemos que La Grecia es una estrofa desgajada de la extensa elegía Messeniènne sur la liberté de la Grèce, de autor anónimo novel publicada en París en el verano de 1821, y de evidente aroma byroniano, pues trata de un dios disfrazado de anciano que acude al Peloponeso a anunciar que la lucha por la libertad y el renacimiento de Grecia ya ha comenzado en Panonia y en las riberas del Euxino, mostrando a un joven sumido en la tristeza por las desgracias de su patria cómo la deidad que anima los escenarios de aquellas hazañas exige rebelión y venganza.

El notable desajuste entre las fechas de publicación del poema en Buenos Aires y en Lima llama poderosamente la atención. Si tenemos en cuenta que el poema sobre el incendio de Cangallo se publicó en el Argos del 30 de marzo de 1822, y que en el Correo de Lima del 22 de junio este poema ya estaba incluido en la Colección que se anunciaba impresa, el Argos del 9 de febrero en el que apareció La Grecia tuvo que haber llegado a Lima mucho antes que el ejemplar con el poema sobre Cangallo, lo que permite postular que los redactores limeños se reservaron La Grecia hasta encontrar el momento óptimo para su publicación, que llegó cuando el poemario patriótico peruano en elaboración estuvo listo para su venta, y La Grecia, por su calidad y su temática, funcionó como reclamo publicitario de prestigio irresistible para su anuncio. Así, $L a$ Grecia apareció publicada en Lima porque responde punto por punto a las necesidades de expresión del discurso patriótico peruano de aquellos días críticos.

No deja de sorprender que un puñado de versos pensados como un mínimo fragmento de un todo acabaran cobrando una insospechada vida propia que les permitió viajar desde París hasta Lima.

El Argos aún publicó otro poema filohelénico en su no 18 del 20/03/1822 ( $v d$. infra en Anexo, Texto 2), que menciona como procedente "de un papel inglés" y cuyo original hemos localizado en el Morning Chronicle, $\mathrm{n}^{\circ}$ 16386, 25/10/1821, 3; esto es, en Londres se publicó antes que La Grecia y en Buenos Aires después de ella. ¿Lo reservaron también los redactores del Argos esperando el momento propicio para su inclusión? Resulta difícil precisarlo, pero la entrada con que se presenta no deja lugar a dudas de que el poema funciona casi como un artículo informativo y que la Revolución Griega era un tema de actualidad que deseaban mantener vivo entre su público:

Los periódicos estrangeros abundan en composiciones poéticas celebrando la revolución actual de la Grecia contra los Turcos. Nosotros que amamos la libertad de todos los hombres de la tierra, que nos hemos inflamado en los conflictos de la patria con la memoria de los sacrificios hechos a la independencia del suelo nativo por los héroes de Atenas y Esparta, nos creemos obligados a insertar en este periódico el siguiente rasgo traducido de un papel inglés.

En su original inglés, este poema presenta el título To Greece y viene firmado por $T$., detalles que desaparecen en la versión española. La traducción libre en endecasílabos blancos deja en segundo plano la fidelidad a la forma original, que, al fin y al cabo, resulta ajena a la tradición literaria propia, y la perfecta adaptación a las estructuras poéticas castellanas lograda por el traductor favorece la asimilación del mensaje.

Los temas son los habituales: invocación a la libertad, rememoración de Esparta y Atenas, exhortación a los griegos a que honren a sus ancestros, que en Salamina y las Termópilas consiguieron vencer a un rey soberbio, y tomen ejemplo de ellos alzando la cruz para que caiga el estandarte de los infieles. El hecho de que este poema fuera concebido como una pieza independiente explica que presente todos los tópicos de la poesía filohelénica, y encontramos ya los dos motivos que faltaban en La Grecia: la confrontación Cristianismo / Islam y la alusión a la historia cultural griega, pues los griegos son movidos a la acción por las voces del sabio y del héroe "que allá un día mandaron en la tierra que hoi oprimen orgullosos tiranos". En la imagen de Grecia como referente de prestigio, armas y letras son inseparables, ya que gracias a esa unión ella fue la primera en enseñar libertad a las naciones, como rezan los versos finales.

Pero los redactores del Argos, los miembros de la Sociedad Literaria de Buenos Aires, aún tenían en cartera otro poema en el que se cantaba la Revolución Griega, si bien lo reservaron celosamente para su publicación estrella, la revista mensual La Abeja Argentina, que comenzó a aparecer por aquellos días en los que Rivadavia mandaba recopilar la poesía nacional para "hacer constar el grado de buen gusto en literatura a que este país ha llegado en época tan temprana". 


\section{Poesía filohelénica en La Abeja Argentina: de Jonia a Buenos Aires}

Como ya se ha mencionado, el objetivo de los Poetas de la Revolución, miembros casi todos ellos de la Sociedad Literaria que emprendió la publicación de La Abeja, era "generalizar conocimientos". Al igual que en El Argos, los redactores seleccionaban los contenidos escrupulosamente para mantenerlos siempre al servicio de su línea editorial, internacionalista e ilustrada, y de ahí que resulte tan relevante que en su primer número dedique ya un artículo a tratar de la Revolución Griega argumentando que:

Cuando todos los papeles públicos de Europa se ocupan de la interesante lucha de la Grecia contra el poder y barbarie Otomana, sería muy reparable que guardase silencio sobre esta grande cuestión del mundo un periódico de Buenos Aires (La Abeja, $\mathrm{n}^{\circ}$ 1, 15/04/1822, 20-22).

El redactor de La Abeja traza una visión panorámica sobre cómo afecta este conflicto a las relaciones entre las potencias europeas e incluye además el Reglamento de Omar el Rhatib, las normas que regían al millet cristiano en el Imperio Otomano con el fin de evidenciar "hasta qué punto han gemido los griegos [...] bajo la terrible glaba (sic) de los turcos y cuánta razón tienen para pelear por su emancipación".

No obstante, los redactores de La Abeja se reservaron el plato fuerte para el mes de mayo, coincidiendo con la celebración y las grandes fiestas cívicas que todos los años se organizaban en conmemoración del aniversario de la Independencia. En su $\mathrm{n}^{\circ} 2,15 / 05 / 1822,77-78$, incluyen un largo poema titulado $A$ la Grecia. Himno ( $v d$. infra Texto 3), cuyos primeros versos no podían por menos que evocar toda la poesía patriótica propia, con idéntico ritmo y prácticamente las mismas imágenes con que se iniciaba el propio Himno Nacional de López y Planes que hemos visto más arriba:

¿Quién sacude esas duras cadenas,

Las quebranta y arroja a sus pies,

Y elevarse más fuerte y soberbia

Que los Reyes armada se ve?

Los temas del poema son los habituales: las cadenas rotas, la lucha a muerte contra la tiranía, los elementos definitorios del neoclasicismo jacobino, la necesidad de libertad para que las "musas divinas" regresen a su hogar, y el enfrentamiento entre Cristianismo e Islam; en definitiva, la civilización contra la barbarie. Al pie figura el lugar, la fecha y unas iniciales: "De Jonia, octubre 7 del 21, Go. Mn."

Este poema quedó olvidado entre las páginas de La Abeja hasta que, seguramente, a raíz de la reproducción de la revista que se incluyó en la Biblioteca de Mayo en 1960, el historiador Alcibíades Lappas se dirige a la Academia Argentina de Letras solicitando información sobre quién podría ser su autor. El académico Roberto Giusti responde desde las páginas del Boletín de la Academia en 1963 que el autor podría haber sido cualquiera de los Poetas de la Revolución, muchos de ellos redactores y colaboradores de $L a$ Abeja, si bien se extrañaba de ello, pues todos eran de formación más virgiliana y romana que griega. Florencio Varela, hermano pequeño de Juan Cruz Varela, el único autor conocido que había escrito un poema sobre la Revolución Griega en 1828, era muy joven en 1822, y tardaría años aún en escribir obras de la madurez de A la Grecia. Himno. Sin resolver el misterio, Giusti concluye que La Abeja no dio importancia a este poema, pues lo encajó en las dos últimas páginas del número en un tipo de letra menor, y que es probable que se tomara de alguna gaceta española, recomendando el Gobierno Municipal su publicación "a modo de adhesión a la causa de Grecia", según las iniciales que aparecen al pie. En 1963 Lappas publica un artículo sobre la presencia de Grecia en la literatura argentina donde, "tras un detenido examen analítico y otros datos" llega a la conclusión de que el poema se debe "nada menos que a la inspiración del propio autor del Himno Nacional argentino, el doctor Vicente López y Planes". Resulta evidente que esta identificación de Lappas se basa en la similitud formal, temática e icónica de ambos himnos, lo que le hace obviar las eruditas consideraciones previas de Giusti ${ }^{8}$.

${ }^{8}$ La Abeja Argentina (Buenos Aires) (1822-1823) [reproducción tipográfica]. Biblioteca de Mayo. Colección de obras y documentos para la historia argentina tomo VI (Literatura), Senado de la Nación Argentina, Buenos Aires 1960, 5239-5700. Las publicaciones aludidas son: Giusti, Roberto. "Consulta acerca del autor del Himno a la Grecia", Boletín de la Academia Argentina de Letras (BAAL) XXVIII, n 107-108, $1963,203-207$. (Reproducido en Academia Argentina de Letras. Acuerdos acerca del idioma, vol. III (1956-1965), Buenos Aires 1983, pp. 264-268.); y Lappas, Alcibíades. "Influencias helénicas en la literatura argentina". Davar. Revista literaria, no 111 (oct.-nov.-dic. 1966), 34-58. Vd. en detalle el 
No obstante, como señala Latorre (2019 I, 546), ninguno de los dos autores parece haber consultado la edición original de La Abeja, en cuyo índice de contenidos del tomo primero se indica: "Himno a la Grecia, traducción del italiano". A partir de ese dato, quedaba descartada la autoría argentina y la cuestión que quedó pendiente de definir era el origen del poema y en qué forma había llegado a Buenos Aires, si en su original italiano o ya traducido, y si las iniciales de la firma correspondían a autor o a traductor.

La respuesta a algunas de esas preguntas se encuentra de nuevo en el Morning Chronicle de Londres, que en su $\mathrm{n}^{\circ} 16400,10 / 11 / 1821,3$, publica el original italiano, cuyo hallazgo constituye una nueva aportación al corpus de poesía filohelénica, ya que aún no se ha hallado referenciado en ninguna otra publicación, ni antigua ni moderna.

Al contrario de lo que opinaba Giusti, Latorre considera que el hecho de que los redactores de La Abeja dedicaran a ese poema más de una página le otorga especial relevancia, y que es muy posible que no sea una casualidad su inclusión en el número de mayo, cuando el aniversario de la Revolución se celebraba por todo lo alto y las efemérides patrióticas propias acaparaban todo el protagonismo.

Enfrentados a un poema en el que la Grecia contemporánea insurrecta convergía con los motivos de raigambre griega y republicana que ellos mismos habían utilizado en su propia poética de liberación — las cadenas rotas, elevarse por encima de los reyes, una voz poderosa que sacude un letargo de siglos, sentir renacer el antiguo valor, la tierra sagrada, expulsar a los bárbaros conquistadores, Aquiles, Esparta, Maratón, Platea, Termópilas...-, esos poetas que luchaban con la espada y la pluma hicieron lo imposible por incluirlo en La Abeja, maquetándolo con una tipografía mínima, y lo difundieron como poesía patriótica propia enriquecida con el siempre irresistible prestigio de lo griego. De nuevo, el uso magistral de la traducción como herramienta para la expansión de ideas y conocimiento convirtió un poema surgido en la lejana Jonia en un himno a la libertad que podría haber nacido sobre cualquier escritorio americano. Como curiosidad, podemos añadir aquí que este poema aún realizó su tornaviaje a Grecia manuscrito en un papel que se ha conservado en el archivo personal de Andreas Luriotis, el agente que el gobierno griego envió a Madrid para negociar un tratado de ayuda con el gobierno español que al final fracasó (Latorre 2012 y 2019 I, 543-544).

\section{Epílogo}

El espacio dedicado a Grecia en el conjunto global del Argos de Buenos Aires y de La Abeja demuestra que la Revolución Griega fue un tema de interés constante para los Poetas de la Revolución que rodearon a Bernardino Rivadavia. Sin entrar en detalle de las noticias de actualidad que recogían entre sus artículos, podemos citar que incluso tradujeron buena parte de la primera Constitución Griega de Epidauro de enero de 1822, una pieza de gran valor documental ${ }^{9}$, pero baste traer aquí un par de citas como prueba de la íntima identificación que percibían entre las revoluciones griega y americana:

La política no ha sido mayormente profundizada en La Abeja. [...] No obstante, como el patriotismo es una calidad que uniforma a todos los miembros del cuerpo, éste bajo aquel respecto ha desplegado en varios escritos un sentimiento firme por la independencia nacional y por la libertad del género humano, incluyendo la patria de los Temístocles y Arístides, cuya resolución por destrozar las cadenas bárbaras de la puerta, la Sociedad ha reconocido tan legítima como la de América por sacudir el pesado yugo de la España (El aniversario de la Sociedad Literaria de Buenos Aires, enero de 1823, apud Biblioteca de Mayo VI, 5709-5710).

GRECIA.- Tiene tanta semejanza nuestra magnánima insurrección con la de los griegos, que es preciso leer con el más vivo interés cuanto se sabe de sus progresos (El Argos, n 71, 03/09/1823, 1).

Y lo mismo ocurre con El Centinela de Buenos Aires:

análisis de este debate en Latorre (2019 I, 544-547). Sobre el poema de Florencio Varela A la libertad de Grecia. Oda, aparecido en El Tiempo (Buenos Aires), $\mathrm{n}^{\circ}$ 47, 28/06/1828, vd. ibidem, 564-571.

${ }^{9}$ El Argos tomó el texto del diario Le Constitutionnel de París, que publicó la Constitución Griega en dos partes el 6 y el 8 de mayo de 1822 , aunque sólo se tradujo la primera parte aparecida en el diario francés, que se dividió a su vez en tres entregas: $\mathrm{n}^{\circ}$ 60,14/08/1821, 1; $\mathrm{n}^{\circ} 61,17 / 08 / 1821,2$; $n^{\circ} 62,21 / 08 / 1822,1-2$. Es posible que los redactores del Argos nunca llegaran a disponer de la segunda parte, lo que explicaría que no publicaran completo el texto de la Constitución Griega. 
Aprovechamos esta ocasión de repetir nuestros votos por el triunfo de los griegos: ellos al cabo pelean contra el despotismo por la libertad, y las regiones en que se adora esta deidad no pueden menos que gloriarse en que se extienda su culto ("Retrato de los griegos", El Centinela de Buenos Aires, ${ }^{\circ}$ 58, 31/08/1823, 125-126).

El Centinela se publicó entre julio de 1822 y diciembre de 1823 por los hermanos Juan Cruz y Florencio Varela e Ignacio Núñez (Zinny 1869, 44). Debemos señalar que en su $n^{\circ} 62,28 / 09 / 1823$, se incluye una larguísima oda $A$ la paz, cuyos primeros cien versos están centrados en la Revolución Griega, cantando de nuevo el sufrimiento de los griegos bajo el dominio de sus tiranos y su valerosa búsqueda de la libertad bajo el recuerdo de sus antepasados. Técnicamente, se podría decir que éste es el primer poema filohelénico argentino original, pero tal afirmación implicaría minusvalorar el poder de la traducción como herramienta no sólo para difundir ideas, sino también para crear textos nuevos que dan respuesta a las necesidades de otros contextos diferentes. Los tres poemas viajeros presentados aquí no son meras traducciones: su proceso de selección, las decisiones sobre su momento óptimo de publicación, y el cuidado que se puso en su recreación para producir piezas poéticas de altísima calidad, son razones suficientes para integrarlos en el acervo literario hispánico que, a su vez, viene a enriquecer por derecho propio el corpus internacional de la poesía filohelénica que, en este momento, en el umbral de la celebración del bicentenario de la Revolución Griega en 2021, está siendo sometido a un profundo proceso de compilación, revisión y reinterpretación.

El filohelenismo que en esta primera época de afianzamiento de la independencia irradia desde Buenos Aires a toda la América hispánica transmuta la admiración inicial a los griegos en una identificación tan íntima con la Revolución Griega que su expresión funciona como un recurso más al servicio de la construcción del propio discurso nacional, a cuya cimentación Grecia, como referente de prestigio incontestable, aportará los valores y las virtudes que la nueva América quería encarnar.

La élite intelectual argentina no sólo celebró la Revolución Griega tanto como la propia, sino que además la consideró como uno de los sucesos internacionales de mayor repercusión e interés por el desafío que suponía para el equilibrio político de la Europa de la Restauración borbónica y de la Santa Alianza. Para ellos, informar sobre los levantamientos contra el despotismo que estaban teniendo lugar en el Viejo Mundo era una forma más de legitimar la propia revolución convenciendo a la opinión pública americana de que la emancipación había sido una causa justa lograda por méritos propios y en consonancia con los tiempos, pues aunque sentían consolidada su nueva identidad desde que se declararon libres de la soberanía española en 1816, nadie los consideró como tales hasta que en 1825 Gran Bretaña dio el primer paso.

No obstante, una vez lograda la libertad, no tardarían en surgir otras Américas. El Partido Unitario de Bernardino Rivadavia, que defendía un centralismo político en el que Buenos Aires sería el centro de control que regiría el resto de las provincias, de inspiración napoleónica y tradición virreinal española, fue tachado de elitista y acabó enfrentado a muerte con el Partido Federalista de Manuel Dorrego, defensor de los intereses de la población rural y de otorgar a las provincias el derecho de autogobierno, y que alcanzó el poder en agosto de 1827. En diciembre de 1828 se iniciaría una guerra civil que finalizó en 1831 con el gobierno del dictador Juan Manuel de Rosas y el exilio masivo de todos los unitarios, que se instalaron mayoritariamente en Montevideo.

Después de los varios trabajos que se han dedicado ya a analizar la recepción de la Revolución Griega y la integración de su contenido ideológico e icónico en el discurso patriótico propio del grupo intelectual unitario de Rivadavia, resultaría especialmente interesante indagar cómo se percibe la lucha de los griegos por su libertad desde periódicos federalistas como El Argentino, El Tribuno o El Republicano, por citar sólo algunos, con el fin de comprobar si sus respectivas percepciones de Grecia y de lo griego son tan irreconciliables y opuestas como ellos mismos.

\section{Anexo documental}

\section{TEXTO 1}

Presentamos el poema La Grèce tal y como se publicó en El Argos de Buenos Aires, n ${ }^{\circ}$ 7, 09/02/1822, 2 , tomado del Morning Chronicle, $\mathrm{n}^{\circ}$ 16393, 02/11/1821, 3. La firma "Un Liberal" no está en el original, siendo un añadido del Argos. El poema debió circular por toda la prensa europea, siendo localizado hasta ahora en Morgenblatt für gebildete Stände (Sttutgart-Tubinga), $\mathrm{n}^{\mathrm{o}}$ 229, 24/09/1821, 916; Flora (Munich), $\mathrm{n}^{\mathrm{o}} 167$, 20/10/1821, 682; Viestnik Evropy [El Heraldo de Europa] (San Petersburgo), vol. 121, no 19 (octubre 1821), 
233-234, y en el folleto a favor de la causa griega Des Grecs, par un philanthrope, Ypres: ImprimerieLibrairie R. Gambart - Dujardin, 1822, xi, atribuido a De Wolff (Droulia 2017, nº 279 / 201).

En realidad, este poema es una estrofa aislada de la obra anónima de 330 versos Messeniènne sur la liberté de la Grèce publicada en París, según Bibliographie de la France, ou Journal Général de l'Imprimerie et de la Librairie, $\mathrm{n}^{\circ} 34,24 / 08 / 1821,455, \mathrm{n}^{\circ} 3372$. La Messeniènne está recogida en los estudios de referencia sobre poesía filohelénica, como Tabaki-Iona $(1993,76)$, y Droulia $\left(2017, \mathrm{n}^{\mathrm{o}} * 110\right.$ /*73), pero hasta ahora no la hemos encontrado asociada a esta estrofa. Debemos señalar que se ha producido una alteración en la transmisión textual pues, en el original, el primer verso dice "sur ces mers que ton regard domine", al igual que en la prensa alemana y rusa, mientras que el folleto belga y el Morning Chronicle presentan "sur ces monts", como El Argos.

La Messeniènne sur la libertè de la Grèce ha sido atribuida al poeta Casimir Delavigne con el único argumento de su título, pues fue quien acuñó el género de la Messeniènne como elegía romántica de tema nacional y patriótico tomando como modelo los cantos con que los mesenios, vencidos por Esparta, expresaban su dolor por la patria perdida, según relata el abate Jean-Jacques Barthélemy en su Voyage du jeune Anacharsis en Grèce, relato de ficción donde se narra el viaje por Grecia del protagonista en el siglo IV a.C., y que desde su publicación en 1788 tuvo un gran éxito, siendo una de las obras que contribuyó al surgimiento de la grecomanía erudita dieciochesca.

Según la reseña firmada por E. H. en Revue Encyclopédique, t. XI, juillet 1821, 610, esta Messeniènne es la primera obra de su autor, y considera que "On y trouve des idées et des expressions très-poétiques déparées par des longueurs et quelques incorrections". La estrofa que nos ocupa debió de ser extraída como uno de los fragmentos más inspirados de la elegía por alguna publicación francesa aún por determinar, y tuvo su propio exitoso recorrido entre San Petersburgo y Lima como poema independiente bajo el título de $L a$ Grèce / La Grecia.

Agradecemos aquí a Theodora Grigoriadou su ayuda para conseguir la reproducción del ejemplar de la Messeniènne sur la liberté de la Grèce de la Biblioteca Nacional de Grecia, con signatura N.Ф. *T 2012, que nos ha permitido confirmar esta identificación:

\section{LA GRÉCE.}

Leve toi! Sur ces monts, que ton regard domine, Vois tu ces flots? C'est Salamine!

Vois tu ces champs? C'est Marathon!

Ces monts? Ce sont les Termopyles!

En souvenirs tous ces champs son fertiles,

Ces rochers ont leur gloire et ces flots ont leur nom.

Oui, l'air même que l'on respire

Est imprégné de gloire et d'immortalité,

Et dans ce flot bruyant, qui sur la grève expire,

Sur ces eaux, dans leurs airs, sur ce roc tourmenté,

Il est un Dieu qui les inspire,

Ils ont une voix, pour te dire,

Gloire, Vengeance, Liberté!

UN LIBERAL

(El Morning Chronicle, Nov. 2)
Traducción.

LA GRECIA.

Álzate! ¿ves desde esos altos montes, que tus ojos dominan, estos mares?

Es Salamina! Ves aquestos campos?

Son los de Maratón! Estas montañas?

Las Termópilas son! Estos lugares

De mil y mil recuerdos siempre abundan,

Estas rocas su gloria, y estas ondas

Su nombre tienen. Sí, aun el aire mismo,

Que se respira aquí, siempre de gloria,

Y de inmortalidad está impregnado,

$\mathrm{Y}$ en estas olas, que a la playa vienen

Ruidosas a espirar, sobre estas aguas,

En su ambiente, sobre esta altiva roca, Hai un Dios que propicio los inflama, Ellos una voz tienen, que incesante

Te grita, Gloria, Libertad, Venganza.

\section{TEXTO 2}

Presentamos el poema publicado sin título en El Argos de Buenos Aires, no 18, 20/03/1822, 1, acompañado de su original localizado en el Morning Chronicle, $\mathrm{n}^{\mathrm{o}} 16386$ 25/10/1821, 3, de gran difusión en la prensa inglesa y norteamericana. Apareció además en el Baldwin's London Weekly Journal, $\mathrm{n}^{\circ}$ 3179, 27/10/1821, 4; Bath Chronicle (Somerset), vol. 64, $\mathrm{n}^{\circ}$ 3113, 01/11/1821, 4; Northampton Mercury, vol. 101, $\mathrm{n}^{\circ} 35$ 03/11/1821, 4; Taunton Courier, $\mathrm{n}^{\circ}$ 690, 07/11/1821, 8; e incluso se da el curioso caso de que el semanario Liverpool Mercury lo publica dos veces en vol. XI, $\mathrm{n}^{\circ}$ 544, 142, y en $\mathrm{n}^{\circ} 548,174$. Semanas después sigue apareciendo en The Gentleman's Magazine (Londres), vol. 131.1, abril 1822, 358. Por ahora, en los Estados 
Unidos lo hallamos en The Ladies' Literary Cabinet (Nueva York), vol. 5, $\mathrm{n}^{\circ}$ 7, 22/12/1821, 55; Sentinel and Democrat from Burlington (Vermont), vol. 12, $\mathrm{n}^{\circ}$ i8?, 18/01/1822, 1; Weekly Raleigh Register, Carolina del Norte, 08/02/1822, 4. El Constitutional Whig de Virginia, vol. 3, $n^{\circ} 30,09 / 05 / 1826,4$, lo publica cuatro años después, lo que demuestra que el poema se mantuvo vivo por la prensa de la época. A pesar de su enorme circulación, no lo hemos encontrado incluido en las compilaciones de poesía filohelénica en inglés de Marios Byron Raizis - Alexander Papas, Greek Revolution and the American Muse, Thessaloniki: Institute for Balkan Studies, 1972, y English Byronic and Philhellenic Poetry of the Greek Revolution, Athens: University of Athens, 1987, https://www.messolonghibyronsociety.gr/philhellenic-poetry/. La versión argentina tampoco está recogida en el compendio de Latorre (2015), por lo que esta edición de original y traducción constituye una nueva aportación al estudio global de la poesía filohelénica.

\section{TO GREECE}

Oh Freedom! how grand would thy triumph be now, After ages of sorrow and gloom,

Should the laurel of Greece be replaced on thy brow, Renewed in its brightness and bloom.

How glorious thy worship again would arise, O'er the thoughts and the spirits of men,

Did thy altar blaze forth beneath Athens' clear skies, And Sparta adore thee again.

Then lose not the moment, ye children of those

Who conquered in Salamis' fight,

Who smote the crowned master of millions of foes,

And sent him back friendless in flight!

Then lose not the moment, ye sons of the brave,

Who died on Thermopylae's shore,

And so well were avenged upon Salamis' wave,

All reddened with proud Persia's gore.

Oh list to the spirits, the glorious and grand!

Who call you from mountain and plain,

'Tis the sage and the hero who once ruled the land

Where tyrants ingloriously reign.

Look round on the tombs of your fathers, whose fame,

In the bright page of history told,

Should teach you to give to your country a name,

Or die like the martyrs of old!

Then raise high the cross, and the infidel's sign

Shall fall before God and the Free!

And Greece! once again shall that freedom be thine

Which mankind first learned of thee!
¡Oh libertad! Qué grande brillaría

Hoi tu triunfo a la faz de todo el orbe,

Si el laurel de la Grecia celebrado

Por su lustre y belleza os adornase

La sien augusta! ¡Qué lleno de gloria

Y magestad tu culto levantara

Sobre los pensamientos de los hombres,

Si brillase tu altar en el hermoso

Claro cielo de Atenas, y tornase

A rendiros Esparta adoraciones!

A las armas corred, o nobles hijos

De los fuertes que un tiempo en Salamina

Consiguieron vencer, y a un Rei soberbio,

Que la tierra abrumaba con sus huestes,

Obligaron a huir, sin que un amigo

Le acompañase en tan adversa suerte.

Apresuraos, o estirpe de los brabos

Que célebre a Termópilas hicieron,

Muriendo en ella por salvar la Patria,

Que vengarse lograron de las aguas

De Salamina, cuando con la sangre

Teñidas fueron del altivo Persa.

$¡ O h$ ! Atended a esos genios de alta gloria,

Que os llaman de los montes y los llanos,

Es el sabio, es el héroe, que allá un día

Mandaron en la tierra que hoi oprimen

Orgullosos tiranos. Vuestros ojos

En las tumbas fijad de vuestros padres,

Cuya fama en la historia conservada,

Os enseña a dar gloria a vuestra Patria,

$\mathrm{O}$ a morir, cual murieron sus Atletas.

Levantad, pues, la Cruz y el estandarte

Caerá de los infieles, a la vista

De Dios, y de los libres; y la Grecia

Recobrará la libertad que supo

La primera enseñar a las naciones.

\section{TeXto 3}

Presentamos el poema A la Grecia. Himno, publicado en La Abeja Argentina, $\mathrm{n}^{\circ}$ 2, 15/05/1822, 77-78, acompañado de su original italiano localizado en el Morning Chronicle, $\mathrm{n}^{\circ} 16400,10 / 11 / 1821$, 2. Si bien la versión argentina está recogida en Latorre $(2015,86-88)$ y analizada en detalle en (2019 I, 542-548), no hemos encontrado el original italiano en ninguna otra publicación de la época $y$, hasta donde sabemos, no aparece citado en los estudios de poesía filohelénica. Si tenemos en cuenta que Gran Bretaña ostentaba entonces la soberanía sobre las Islas Jónicas, es posible que hubiera llegado a Londres en alguna de las 
gacetas que allí se publicaban a partir del círculo de poetas filohelenos como Ugo Foscolo o Andreas Mustoxidis. Las iniciales al pie del poema continúan siendo una incógnita.

\section{TO GREECE}

INNO

Che è costei che le ferre ritorte

Squassa, frange, concalca col pié,

Ed' un brando impugnato, più forte

Più superba s'estolle dei Rè?

Arde, freme, ed' all Attico lido

Rivolgendo lo sguardo ella và...

Ah! di Grecia la Donna, qual grido

Quell'aspetto palese già fá:

$\mathrm{O}$ voi Figli dell' inclita gente

Che di Serse l'audacia fiaccò

Dite voi quella voce possente

Dal lettargo alla fin vi destò?

$\mathrm{Ah}$ ! si il grido belligero ascolto

Già risorge l'antico valor:

Scosso è il giogo; già imbiancassi il volto

Di Bisanzio l'imbelle Signor.

Già di Dacia, di Mesia le Schiere

Fan preludio a più chiaro destin

Che fugate le Odrisci bandiere

Dell' Alloro si cinsero il Crin.

E già Sparta, Messenia, a la Terra,

Che di Pallade vanta il favor,

L'Inno sacro intonando di Guerra

De' tiranni sfidaro il furor.

Ah! dell' ardua ma nobile impresa

Cittadini, non tocarssi il piè

Dio protegge in si fiera contèra

Chi difende la Patria la fè.

Regni in mezzo alle Grece falangi

Una mente, un volete, un ardir;

Giuri ogn'uno, né il giuro s'infrangi

Là di vincere ovver di morir.

Che più induggi! ecco farvi corona,

Per gli'azzuri dell' Etra sentier

Quei di Leutra, Platea, Maratona,

Invittissimi prischi guerrier.

Fino a quando da Traci calpesta

Quella Terra un di sacra, vedrò,

Ove, pieno d'un nume la Testa

Le sue leggi Licurgo dettò;

Quella Terra, ove ardito tornava

Di Filippo il nemico maggior,

Ove Omero gli spirti inflammava

Del Pelide cantando il furor?

Fino a quando le blonde camene

Da' bel Colli raminghe saran?

Fino a quando del sacro, Ippocrene,

Traci armenti nell onda benian?

E chi mai l'ingiustissimo acquisto

Pensa al barbari ancora serbar!

Chi voria la Gran Tomba di Cristo

Sempre in mano de Cani lasciar?

\section{A LA GRECIA \\ HIMNO}

¿Quién sacude esas duras cadenas,

Las quebranta y arroja a sus pies,

Y elevarse más fuerte y soberbia,

Que los Reyes, armada se ve?

Arde, brama, y al Ático suelo

Revolviendo la vista ella va...

$\mathrm{Ah}$ ! Su aspecto, en el grito, nos dice

Que es la Grecia Matrona inmortal:

Nobles hijos de la ínclita gente,

Que de Xerxes la audacia domó,

Decid, pues, ¿esa voz poderosa

Del letargo por fin os sacó?

$\mathrm{Ah}$ ! Si el grito belígero escucho,

Ya renace el antiguo valor:

Roto el yugo, se espanta y aterra

De Bisanzio el inerme Señor.

A los bravos de Dacia, y de Mesia

A la gloria ya vemos correr,

Que la Oderica hueste humillada

Se ciñeron de eterno laurel.

Y ya Esparta, Mesenia y la tierra

Que de Palas exalta el favor

Con el himno de guerra sagrado

Desafiaron al cruel opresor.

$\mathrm{Ah}$ ! en tan ardua, mas noble carrera

Una frente serena oponed,

Dios protege en tan fiera contienda

Al campeón de la patria, y la fe.

Reine en medio a las griegas falanges

Una mente, un querer, un ardor;

Jurad todos, ninguno perjure,

$\mathrm{O}$ vencer, o morir con honor.

¿Qué dudáis! Ved que os tejen coronas

Por la etérea sublime región

Los que gloria inmortal consiguieron

Allá en Leutres, Platea y Maratón.

Hasta cuándo del Tracio pisada

Esa tierra sagrada será,

Do Licurgo sus leyes sabía,

Cual un numen divino, dictar;

Esa tierra en que osado tronaba

De Filipo el contrario mayor,

Do inflamaba a los hombres Homero

De un Aquiles cantando el furor?

Hasta cuándo las musas divinas

De los gratos collados huirán?

Hasta cuando en el sacro Hipocrene

A beber los ganados vendrán?

Y quién piensa la horrible conquista

A la bárbara gente guardar!

Quién querrá la gran tumba de Cristo

Entre manos sangrientas dejar? 
"Ah! se il vile pensier sulla Terra "V'ha chi nutra sia popolo o Rè

“Sappian pur, ch'a giustissima guerra

"Sempre avverso il destino non è.

"Ed oh! possan nell' empio cimento

"In ogn'anima Greca trovar,

"Disperato l'ardir de'Trecento

"Ch'in Termopile li sangue versar."

Go. MN.

From Ionia, Oct. 7. 1821
No haya pueblo, ni rey en la tierra,

Que alimente tan bajo pensar,

Que no siempre contrario el destino

En tan santa contienda será.

Que en cada uno de los fuertes griegos

Pueda el cruel enemigo encontrar

El despecho de aquellos que dieron

A Termópilas nombre inmortal.

Go. MN.

De Ionia, octubre 7 del 1821

\section{Referencias bibliográficas}

Barcia, Pedro Luis (2001), "La inédita Colección de poesías patrióticas", Boletín de la Academia Argentina de Letras, $\mathrm{n}^{\circ}$ 259-260, enero-junio 2001, pp. 109-145.

Berenguer Carisomo, Arturo (1947). Las ideas estéticas en el teatro argentino. Buenos Aires: Instituto Nacional de Estudios de Teatro.

Burucúa, José Emilio, Andrea Jáuregui, Laura Malosetti, Ma Lía Munilla (1990), "Influencia de los tipos iconográficos de la Revolución francesa en los países del Plata”, en François-Xavier Guerra (ed.). L'Amérique latine face à la Révolution française. L'Héritage révolutionnaire: une modernité de rupture, Cahiers des Amériques latines, ${ }^{0} 10$, 1990, pp. 147-157.

Disponible en: http://www.iheal.univ-paris3.fr/sites/www.iheal.univ-paris3.fr/files/Cal_010.pdf

Chenot, Beatriz (2000), "De las colecciones de poesías patrióticas a la antología literaria. La Lira Argentina, El Parnaso Oriental y América poética", en Geneviève Champeau (ed.). Le phénomène anthologique dans le monde ibérique contemporain. Bordeaux: Presses Universitaires de Bordeaux, pp. 171-188.

De Lorenzo Álvarez, Elena (2004), "La construcción de una identidad: el mundo indígena en la literatura independentista (La Lira Argentina)", América sin nombre, no 5-6, 2004, pp. 130-137. Disponible en: https://core.ac.uk/download/pdf/16359535.pdf

Díaz-Caballero, Jesús (2005), "El incaísmo como primera ficción orientadora en la formación de la nación criolla en las Provincias Unidas del Río de la Plata", A Contracorriente: Revista de Historia Social y Literatura en América Latina, $\mathrm{n}^{\circ} 3.1,2005$, pp. 67-113.

Disponible en: https://projects.ncsu.edu/project/acontracorriente/fall 05/Diaz-Caballero.pdf

Droulia, Loukía (2017). Philhellénisme. Ouvrages inspirées par la Guerre de l'Indépendance Grecque, 1821-1833. Répertoire bibliographique, seconde édition revue et augmentée. Athènes: Fondation Nationale de la Recherche Scientifique.

El Argos de Buenos Aires, no 1-99 (1931)[abril 1821-diciembre 1822]. Reimpresión facsímile dirigida por los señores Antonio Dellepiane, Mariano de Vedia y Mitre y Rómulo Zabala, y prologada por el señor Arturo Capdevila. Biblioteca de la Junta de Historia y Numismática Americana, vol. X. Buenos Aires: Atelier de Artes Gráficas "Futura", 1931.

Disponible en: https://hdl.handle.net/2027/uc1.c2989016

Homenaje = ler Homenaje del Perú en 1822 al Libertador José de San Martín. Obra de los Poetas de la Revolución. Colección de algunas poesías publicadas desde la entrada del Ejército Libertador en la Ciudad de los Libres (1975). Ed., intr. y notas de Peraltilla Díaz, Artemio. Arequipa: Editorial Peraltilla.

La Abeja = La Abeja Argentina, vol. 1, no 1-9 (abril-diciembre 1822), Buenos Aires.

Disponible en: https://books.google.es/books?id=1-kpAAAAYAAJ

La Lira 01 = La Lira Argentina, o Colección de las piezas poéticas dadas a luz en Buenos-Ayres durante la Guerra de su Independencia [Facsímil de la original de 1824]. Biblioteca de Mayo. Colección de obras y documentos para la historia argentina, t. VI (1960). Senado de la Nación Argentina, Buenos Aires, pp. 4693-5237.

La Lira 02 = La Lira Argentina, o Colección de las piezas poéticas dadas a luz en Buenos-Ayres durante la Guerra de su Independencia (1982). Ed. crítica, estudio y notas por Pedro Luis Barcia. Buenos Aires: Academia Argentina de Letras.

Disponible en: http://bib.cervantesvirtual.com/servlet/SirveObras/72399281642354618671902/index.htm

Latorre Broto, Eva (2012), "Los amigos de la libertad: documentos sobre el filohelenismo español (1821-1823)", Erytheia, no 33, 2012, pp. 195-251.

Disponible en: $\mathrm{https}: / /$ www.academia.edu/40597562/

Latorre Broto, Eva (2015). Griegos que el estandarte alzáis de libres. Poesía filohelénica española e hispanoamericana (1821-1843). Estudios y Textos de Erytheia, 8. Madrid: Asociación Cultural Hispano-Helénica.

Disponible en: https://www.academia.edu/40601880/ 
Latorre Broto, Eva (2019). Filohelenismos hispánicos. Lo griego como referente de autorrepresentación en los discursos ideológicos de España e Hispanoamérica (1821-1824), 2 vols. Tesis doctoral. Madrid: Universidad Complutense de Madrid.

Disponible en: https://www.academia.edu/41029829/

Lescano, Mariana Paula (2015), "La prensa durante el período rivadaviano: El Argos de Buenos Aires (1821-1825)", Almanack. Guarulhos, no 9, 2015, pp. 136-152.

Disponible en: http://dx.doi.org/10.1590/2236-463320150910

Monguió, Luis (1961), "La controversia literaria sobre «Las ruinas de Pachacamac», Lima, 1822”, Revista Iberoamericana, n 26-27, 1961, pp. 81-110.

Disponible en: https://doi.org/10.5195/reviberoamer.1961.2008

Monguió, Luis (1972), "La poesía y la independencia, Perú 1808-1825”, en Literatura de la Emancipación Hispanoamericana y otros ensayos. Memoria del XV Congreso del Instituto de Literatura Iberoamericana, $2^{a}$ sesión en Lima (9-14 de agosto de 1971). Lima: Universidad Nacional Mayor de San Marcos, pp. 7-15.

Quinziano, Franco (2011), "Il Trienio Liberal Spagnolo nel Rio de la Plata (1820-1824). El Argos de Buenos Aires ed El Centinela, tra affinitè e diffidenze", Eadem Utraque Europa, año 7, no 12, junio 2011, pp. 79-114.

Disponible en: https://www.academia.edu/2438025/

Suárez, Carlos A. (1984), "La Revolución Griega de 1821. Repercusión en Buenos Aires”, Revista de la Universidad de Morón, $\mathrm{n}^{\mathrm{o}}$ 11, noviembre de 1984, pp. 137-147.

Tabaki-Iona, Fridériki (1993). Poésie philhellénique et périodiques de la Restauration. Athènes: Société des Archives Helléniques, Littéraires et Historiques.

Tolias, Georgios (2017), “The resilience of Philhellenism”, The Historical Review/La Revue Historique, n 13, $2017, \mathrm{pp}$. 51-70.

Disponible en: http://dx.doi.org/10.12681/hr.11556

Zanou, Konstantina (2015), "Europe's imaginary of ancient and modern ruins: Hellenism and Philhellenism”, en Omar Kholeif (ed.). Two Days After Forever: A Reader on the Choreography of Time. Berlin and New York: Sternberg Press, pp. 36-49.

Disponible en: https://www.academia.edu/12070402/

Zinny, Antonio (1869). Efemeridografía Argirometropolitana hasta la caída del gobierno de Rosas. Buenos Aires: Imprenta del Plata, 1869. 